\title{
Evaluation of patient's satisfaction in the surgical units in a tertiary care public hospital
}

\author{
Bhoir L. $\mathbf{N}^{1}$, Sarda $\mathrm{A}^{2}$, Jhingan $\mathbf{M}^{3}$ \\ ${ }^{1}$ Dr. Lata N. Bhoir, General Surgery, Associate Professor, Department of General Surgery, B. J. G. M. C., Pune. \\ ${ }^{2}$ Dr. Astha Sarda, Junior Resident III, Department of General Surgery, B. J. G. M. C., Pune. ${ }^{3}$ Dr. Mrida Jhingan, Junior \\ Resident I, Department of Anaesthesia, J. J. M. C., Mumbai, India.
}

Address for correspondence: Dr. Lata N. Bhoir, Associate Professor, Department of General Surgery, B. J. G. M. C., Pune. Email: lbhoir03@gmail.com

\begin{abstract}
Introduction: In the modern era, it is not only the right of every patient to demand best possible medical care in Government runs Hospitals, but it is the moral and legal obligation of every health care provider as well, to deliver his optimum efforts to the entire satisfaction of the patient. Methods: A pre formed questionnaire and personal interview of 350 patients was carried out to determine the level of satisfaction among patients. Results: Most of the patients were found to be more than satisfied in most of the categories of questions asked. Conclusion: Overall assessment of the whole process through this study gave us an opportunity to find loopholes and deficiencies in our services for any future remedial action. The response given by the patients at the end of the data collected enabled us to make any suggestions so as to improve the quality of the services rendered at the hospital.
\end{abstract}

Keywords: Pre formed questionnaire, Satisfaction level

\section{Introduction}

A health system consists of all organizations, people and actions whose primary intent is to promote, restore or maintain health [1]. A health care provider may be an individual or an institution that provides preventive, curative, promotional or rehabilitative health care services in a systematic way to individuals, families or communities. The Indian healthcare industry is seen to be growing at a very rapid pace. Health care organizations in the country are operating in an extremely competitive environment and hence, it is imperative that along with all the facilities being available, there has to be a certain level of patient satisfaction as well [2].

Government hospitals, being amongst the best hospitals in India, provide treatment either free of cost or at minimal charges. The In-hospital treatment charges are levied depending upon the financial condition of the patient, all facilities being free of charge for people below poverty line. However, Indian public health

Manuscript received $9^{\text {th }}$ May 2016

Reviewed: $17^{\text {th }}$ May 2016

Author Corrected: $28^{\text {th }}$ May 2016

Accepted for Publication $11^{\text {th }}$ June 2016 system faces many challenges, which needs to be addressed, in order to improve the existing health care facilities. Despite having numerous centers of excellence in healthcare delivery, these facilities are limited and are inadequate in meeting the current healthcare demands.

With the economic progress of the nation, there is an increase in the income as well as the education level of the people. There is also, an increase in the awareness level of the consumers, thus enabling them of making well informed decisions about their health and the associated implications. Hence it is necessary to improve not only operational efficiency but also, to provide customer friendly patient centered services and look at other ways of enhancing patient experience overall [3].

The Hospital system must take care of a patient, right from the time he/ she makes his/ her first presence in the Hospital till the time he/she is discharged from the hospital [4]. It is only then that a Hospital can claim to be fulfilling its social obligation and responsibility 
towards the civic society. The basis of the present study is to find the magnitude of satisfaction amongst patients in the surgical units in a tertiarycare public health system. People from rural as well as urban areas of the State as well as the adjacent states visit these hospitals directly or are referred to by other hospitals.Thus, it becomes absolutely essential to know how satisfied these patients are, and to find the cause, if any, of discontent amongst the patients, so as to improve the overall health care system. Overall assessment of the process and the factors leading to the dissatisfaction of the patients helps us in devising suitable measures so as to improve the health care experience for patients [5].

\section{Materials and Methods}

- Study design: Cross sectional study

- Study area: Tertiary care public hospital.

- Data Collection Method: Pre-formed Questionnaire and Personal Interview.

- $\quad$ Sample size: 350 .

\section{Inclusion criteria}

1. Patients with a minimum stay of five days in the ward.

\section{Exclusion criteria}

Patients who underwent day care procedures or had a stay of less than five days.
The study was carried out in the following steps:

1. Live interactive studies and the findings as a result of interaction with 350 patients: The patients were explained the nature and exact purpose of the research program. They were then asked for consent for taking part in the research program. The patients were reassured that their privacy and confidentiality would be maintained and only the statistical data would be utilized. The patients were interviewed with a preformed questionnaire. The first part of the questionnaire consisted of variables such as age, sex, occupation and education whereas the second part consisted of questions specific for assessing patient satisfaction. Answers to the second partwere graded as per Likert's scale [questionnaire attached]. In cases when the patient was unable to take part in the program as in the case of minors/comatosed, the parents/guardians should be interviewed.

2. Critical and unbiased comprehensive review of findings of the data collected in the present research study was done:

The data was compiled using MS Office Excel application. This data was then statistically analysed using the SPSS software version 11 for the outcome for indices of patient satisfaction. Patients were also categorized into three categories- fully satisfied, partially satisfied and not satisfied.

\section{Results}

Age and sex wise distribution among study group shows majority of study subjects are Male compared to females. Maximum number of subjects i.e. 64 is in age group of 51 to 60 followed by 57 in 41 to 50 and 52 in 31 to 40 year age group [figure 1].

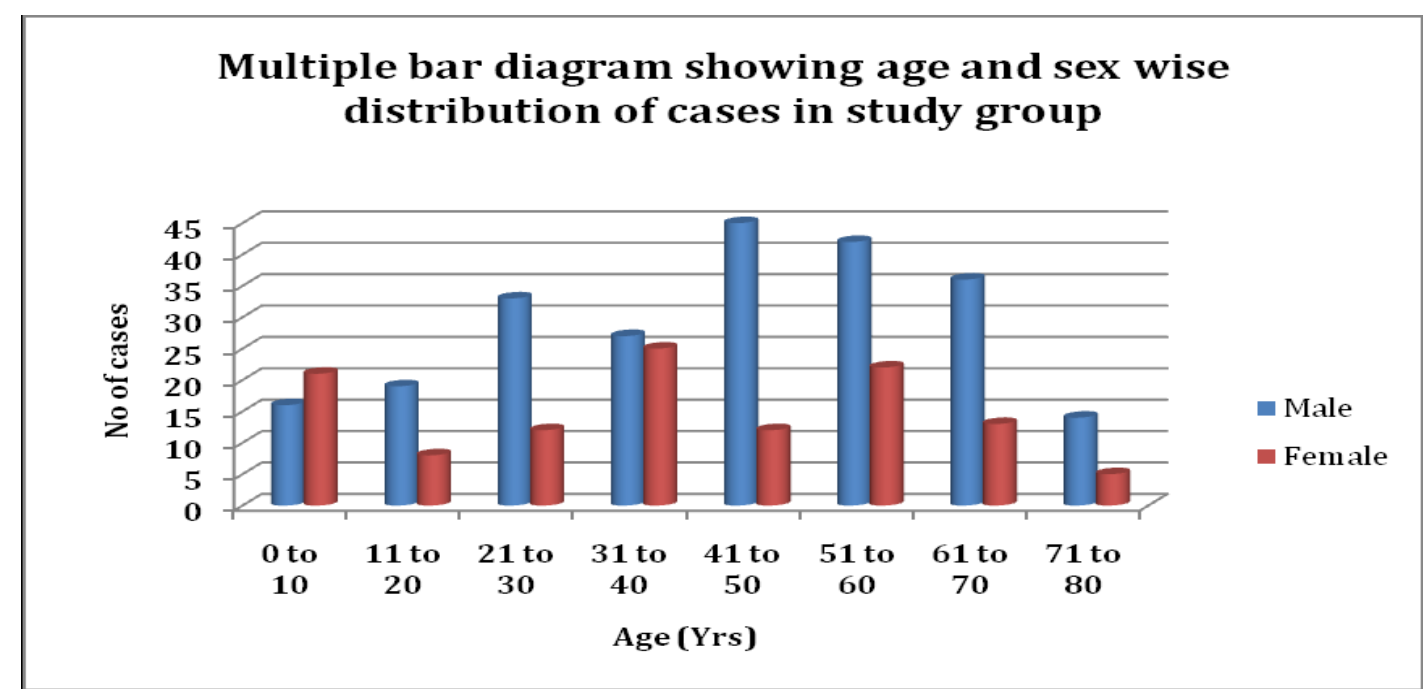

Figure-1: Age and sex wise distribution 
Ration card colour wise distribution among study group shows majority of study subjects i.e. 134 [38.2\%] are having orange colored ration card followed by 119 [34\%] have yellow colored i.e. below poverty line ration card. 16 subjects have white colored ration card.

Occupation wise distribution among study group shows majority of study subjects i.e. 74 [38.2\%] are either labourers or doing service. 55 [15.71\%] of subjects are unemployed. 14.29\% [50] are doing agriculture work and 46 of women are housewife.

Education wise distribution among study group shows majority of study subjects i.e. 133 [38\%] are educated up to secondary and higher secondary level followed by $30 \%$ of subjects illiterate and $27.14 \%$ [95] are educated up to primary level. Remaining 17 subjects are graduates.

Satisfaction level wise distribution among study group shows majority of study subjects i.e. 196 [56\%] are fully satisfied with services rendered followed by 153 [47.7\%] are partially satisfied and one subject not satisfied with services provided.

Table-1: Distribution of cases as per satisfaction level scale for the various service components:

\begin{tabular}{|c|c|c|c|}
\hline & \multicolumn{3}{|c|}{ Satisfaction level } \\
\hline Service component & Fully satisfied [\%] & Partially satisfied [\%] & Not satisfied [\%] \\
\hline Access- availability- convenience & 72 & 25.71 & 2.29 \\
\hline Communication & 9.14 & 59.43 & 1.43 \\
\hline General satisfaction & 85.71 & 12.86 & 1.71 \\
\hline Interpersonal aspects & 52.86 & 45.43 & 1.43 \\
\hline Technical quality & 45.71 & 52.86 & 0.28 \\
\hline General questions & 84.86 & 14.86 & \\
\hline
\end{tabular}

Average satisfaction levels: [figure 2] [table 2]

Average satisfaction levelsfor the various sub-scales were found to be:

- General questions category: $84.82 \%$

- General satisfaction category: $83.59 \%$

- Access- availability- convenience: $80.33 \%$

- Interpersonal aspects: $74.74 \%$

- Technical quality: $71.70 \%$.

- Communication: $54.02 \%$.

Table-2: Average satisfaction levels for various service components.

\begin{tabular}{|c|c|c|c|c|}
\hline Service component & No of items & Maximum score & Average Score & Satisfaction level \\
\hline Composite score & 30 & 150 & 112.3 & 74.87 \\
\hline $\begin{array}{c}\text { Access-availability- } \\
\text { convenience }\end{array}$ & 5 & 25 & 20.08 & 80.33 \\
\hline Communication & 5 & 25 & 13.51 & 54.02 \\
\hline General satisfaction & 5 & 25 & 20.90 & 83.59 \\
\hline Interpersonal aspects & 5 & 25 & 18.69 & 74.75 \\
\hline Technical quality & 5 & 25 & 17.93 & 84.82 \\
\hline General Questions & 5 & 25 & 21.21 & \\
\hline
\end{tabular}

Mahapatra [7] in his study, however showed that highest level of satisfaction was found in the communication category with $76 \%$ which happened to score the lowest ratings in our study. The overall satisfaction level was found to be $74.87 \%$, a slightly higher percentage as compared to other studies carried out in the same field by others like Mahapatra [7] with an overall satisfaction level of $65 \%$. 
Access- availability- convenience:

- $73 \%$ patients agreed that the admission process was carried out promptly. $74 \%$ of them also agreed that the registration process was easy and convenient to carry out.

- $85 \%$ said that emergency treatment was available easily.

And $86 \%$ thought that there was easy access to medical specialists and staff. However, only $63 \%$ of patients thought that the hospital was conveniently located.

- The overall scores in the access-availability- convenience subscale were very similar to those seen in study by Mahapatra [7] where this sub-scale had an overall level of $73 \%$ satisfaction.

- Communication:

- $55 \%$ of the patients were of the opinion that they were given adequate information about the clinical illness/ disease they were suffering from.

- $43 \%$ of them thought that the proposed course of treatment was adequately explained to them.

- $63 \%$ agreed that the doctors were good at explaining to them, the various precautions, post-operative care, side-effects and complications of the treatment.

- On the other hand, only $45 \%$ thought they were adequately informed about the reasons for which the various tests were being carried out. In the study carried out by Mahapatra [7] however, it was seen that $77.1 \%$ of the patients thought that they had been adequately informed about the various tests and the reasons for which they were carried out.

- Only, 3.7\% of the patients in our study felt that they were made aware of alternate courses of treatment mentioning the advantages and disadvantages of each course of treatment.

\section{Discussion}

It will not be out of the place to say that there is an acute shortage of literature in this particular subject matter. Nevertheless, the following researchers have done a commendable job in the related field.

A study was carried out by Arpita Bhattacharya et al in the Advanced Pediatric Center (APC) of a public sector Tertiary hospital. Overall level of satisfaction with doctors was found to range from $89.3 \%$ to $99.6 \%$. Very high levels of satisfaction were expressed on technical quality of doctors' work and their approachability. The level of satisfaction with behavior and attitude of nurses towards the attendants was poor. $24.2 \%$ attendants thought that some of the nurses were rude. Moderate level of satisfaction score was noted regarding quality of work of ward servants/sweepers. More than $94.5 \%$ of the attendants responded positively to the general cleanliness and food [6].

Prasanta Mahapatra et al carried out a study in 25 District or Area Hospitals in Andhra Pradesh. Overall level of satisfaction with services stood at $65 \%$. Lowest level of satisfaction was found in the General satisfaction sub scale. Next lowest level of satisfaction score was obtained by the time spent with doctor and technical quality sub scales. Both these sub scales had items designed to measure patients assessment of doctor's work [7].
In a study carried out by Sodani PR et al for the Outpatient Department patients in public health facilities of Madhya Pradesh, it was seen that most of the respondents were youth and had low level qualification levels. Patients were more satisfied with the basic amenities at higher health facilities compared to lower level facilities [8].

A similar study was also carried out in Rawalpindi by Abida Sultana et al. Attitude and behavior of healthcare providers was found to be satisfactory. However, some fundamental conveniences and general sanitary conditions were in need of due consideration by the management for the betterment of patients [9].

Mikael Rahmqvist carried out a study to evaluate the inpatient care at a hospital in Sweden and related patient satisfaction to age, health status and other background factors such as pain. Scores on the Patient Satisfaction Index were found to increase with age, with the highest mean being in the age group 75-84 years. The groups with the highest PSI scores were also found to contain the greatest proportion of patients with poor health. For pain and anxiety, however, the distribution was negative compared with age with a peak in prevalence for the age group 15-24 years [10]. Another study was carried out by TalluruSreenivas et al in three different hospitals in Hyderabad, one owned completely by the 
Government, one under private management and one which runs on corporate lines under the control of State Government. The objective of the study was to find out how far the high technology hospitals had attained their organizational goals. It was found that the satisfaction level was least in the Government Hospital with majority of the respondents claiming that the facilities at the investigation room where not good. Most of the respondents were also not happy with the behavior of the staff and they claimed to have experienced discrimination while receiving treatment [4].

Another study was carried out on similar lines by S. A. Deva et al in Kashmir. $80 \%$ of patients attending the OPD were found to be satisfied. The reason for the dissatisfaction in the remaining $20 \%$ was correlated to the less service time given to the patients [3].

A similar study was carried out by Ranjeeta Kumari et al in Government Allopathic Health Facilities in Lucknow. Accessibility was a problem for $42 \%$ patients and waiting time was more than $30 \mathrm{~min}$ for $62.5 \%$. The overall satisfaction regarding the doctor-patient communication was more than $60 \%$ but that with the examination and consultation was less than $60 \%$. The most important motivating factor for the visit to the tertiary $(48.2 \%)$ and secondary level $(71.9 \%, 67.1 \%)$ of health facilities was the faith on doctors or health facility [2].

\section{Satisfaction grading in individual sub-scales: [table 1]}

- Satisfaction level was highest in the general satisfaction component [including questions regarding the overall treatment meted out to the patients and their grievance and complaints being adequately addressed] with $85.71 \%$ patients being fully satisfied, $12.86 \%$ being partially satisfied and only $1.43 \%$ being not satisfied.

- In the general questions category [including questions regarding the affordability of the treatment, their desire to visit the hospital again and timely medications being given], $84.86 \%$ were fully satisfied, $14.86 \%$ were partially satisfied and only $0.28 \%$ were not satisfied.

- In the access-availability- convenience category, $72 \%$ were fully satisfied, $25.71 \%$ were partially satisfied and $2.29 \%$ were not satisfied.

- For interpersonal aspects, $52.86 \%$ patients expressed full satisfaction, $45.43 \%$ expressed partial satisfaction and only $1.71 \%$ expressed no satisfaction.
- Satisfaction levels were found to be the lowest in matters of technical quality [including questions on services, facilities, food, ward bathroom cleanliness] and communication [including question regarding adequate information being given to the patient about the disease, illness, course of treatment, and the various effects of the treatment].

- In the Technical quality category, $45.71 \%$ patients were found to be fully satisfied, $52.86 \%$ were found to be partially satisfied and $1.43 \%$ were found to be not satisfied.

- In the study carried out by P Mahapatra [7], subscale carrying questions similar to this category had the lowest level of satisfaction.

- In the communication sub-scale, only a mere 9.14\% sample size was fully satisfied, with partially satisfied patients constituting $59.43 \%$ and not satisfied patients constituting $31.43 \%$ of the sample size. This is in stark contrast to the study carried out by P Mahapatra [7] where highest level of satisfaction was found in this category.

\section{General satisfaction:}

- Satisfaction levels were much higher in this subscale, with $94 \%$ of the patients being satisfied with the answers given by the doctors to questions bothering them.

- The satisfaction level was slightly less when it came to the nurses, with only $78 \%$ of patients being satisfied with the answers given to them by nurses to questions bothering them.

- $68 \%$ of patients thought their grievances and complaints were adequately addressed.

- $93 \%$ of them were satisfied with the way they were treated at the hospital and their overall communication with the doctors and the nursing staff.

- This is similar to the results of study carried out by A. Bhattacharya [6] where the overall satisfaction level towards the doctor ranged from $89.3 \%$ to $99.6 \%$. The percentage of satisfied attendants regarding technical aspects of nursing care in the study was also above $90 \%$.

- Interpersonal aspects:

- $95 \%$ of the patients felt that the doctors were polite, efficient and helpful.

- On the other hand, only $79 \%$ of them were of the opinion that the nurses and staff were polite, efficient and helpful. In the study carried out by A. Bhattacharya [6] it was seen that $24.2 \%$ attendants 
thought that some of the nurses were rude and 21.4 $\%$ had felt they were indifferent.

- $10 \%$ of our study group said that the ward boys accompanied them when various tests and procedures had to be carried out.

- $81 \%$ of them were of the opinion that the staff was very helpful during the registration process of the hospital.

- Corruption was not an issue in the hospital as per $89 \%$ of the patients interviewed whereas it was found to be the top area of concern according to $20 \%$ of the patients in the study carried out by Mahapatra [7].

\section{Technical quality:}

- $93 \%$ of the patients thought that the services and the quality of treatment at the hospital were satisfactory.

- $63 \%$ felt that the hospital had everything needed to provide complete medical care to a patient.

A. Bhattacharya [6] in her study stated that $62.7 \%$ of the attendants had responded saying that the hospital provided best facilities.

- Only $39 \%$ of the patients in our study found the food satisfactory.

- $69 \%$ of them felt that the wards were clean while only $37 \%$ of the patients felt that the toilets and bathrooms were adequately clean.

In the study carried out by Mahapatra [7] on the other hand, $81.1 \%$ of the patients were satisfied with the cleanliness of the hospital and $61.1 \%$ felt that the toilets were not adequately maintained in the hospital.

\section{General questions:}

- In the sub-scale of general questions, $96 \%$ of all patients thought that all injections/ medications were given to them on time.

- $91 \%$ felt that they were frequently visited by the doctor in the day.

- Only $47 \%$ of the people thought that the services were affordable.

- Inspite of this, $97 \%$ of the patients said that they would visit the hospital again if needed and would recommend the hospital to their friends and relatives. However, most of them responded by saying that they would have to return as they had no other option due to their low socio-economic conditions and high expenditures in the private hospitals.
Patient satisfaction index [PSI]: PSI was constructed using two questions concentrating on the overall evaluation of duration of hospital stay as mentioned in the questionnaire. Each question had alternative answer in the range of 1 to 5 . The two questions were

1. Over all you are satisfied by the way you are treated at the hospital [Mean 4.33, SD 0.68]

2. You will recommend this hospital to your friends /relatives in case they require any medical treatment. [Mean 4.44, SD 0.65]

The Pearson product moment correlation was 0.43 for the two questions constituting the PSI, which indicates a good inter-reliability.

\section{Conclusion}

The patient satisfaction survey was the first of its kind carried out in this Tertiary care public sector Hospital. It helped determine the overall patients' satisfaction level in the Surgical units of the Hospital to be $74.87 \%$ which was much higher than similar studies carried out previously in other tertiary care Public sector hospitals.

Most of the patients were found to belong to low socioeconomic strata of society with maximum number of patients having saffron colour ration card and majority of them working as labourers and Government employees.

The main areas of concern and dissatisfaction were found to be inadequate communication between doctor and patients, unsanitary condition of the bathrooms, the quality of the food provided and affordability of the entire treatment. The patients were also dissatisfied with the services provided by the ward boys.Doctor- patient communication, cleanliness, food supply and cost of the treatment were found to be the main factors leading to dissatisfaction amongst the patients.

An attempt to evaluate the level of satisfaction related to different parameters of quality health care thus helped us ascertain the areas requiring corrective action to be taken to improve the hospital's service quality. Overall assessment of the process and the factors leading to the dissatisfaction of the patients gives us an opportunity to find loopholes and deficiencies in our services for any future remedial action and also helps us in devising suitable measures so as to improve the health care experience for patients. Collection of data from the general population and analyzing the data 
leads to a critical information about a given facility. The feedback can be taken as constructive criticism by the doctors, the nurses and other hospital personnel, which helps in improvement of the hospital services and increases the satisfaction level of the patient.In conclusion, the Tertiary Care Public Hospitals have no option but to adopt a more patient centered approach and hence should aim for maximum patient satisfaction as that is the ultimate aim of the public health provider.

Funding: Nil, Conflict of interest: None initiated. Permission from IRB: Yes

\section{References}

1. WHO, 2007. Everybody's business. Strengthening health systems to improve health outcomes : WHO's framework for action.

2. Kumari R, Idris M, Bhushan V, Khanna A, Agarwal M, Singh S. Study on patient satisfaction in the government allopathic health facilities of Lucknow district, India. Indian J Community Med. 2009;34 (1):35.

3. S.A. Deva, M. Haamid, J.I. Naqishbandi, SM Kadri, S. Khalid, N. Thakur. Patientsatisfaction survey in Outpatient Department of a Tertiary care Institute. Journal of Community Medicine, Jan-June, 2010, Vol. 6 [1]

4. Talluru Sreenivas, G. Prasad. Patient Satisfaction - A Comparative Study. Journal of the Academy of Hospital Administration [2003-07 - 2003-12]; Vol. 15, No. 2.
5. Repert MI, Babakus E. Linking quality and performance. Quality orientation can be a competitive strategy for health care providers. J Health Care Mark, 1996;16:39-43.

6. Arpita Bhattacharya, Prema Menon, Vipin Koushal, K. L. N. Rao. Study of Patient Satisfaction in a Tertiary Referral Hospital. Journal of the Academy of Hospital Administration, [2003-01 - 2003-06],Vol. 15, No. 1

7. Prasanta Mahapatra, Srilatha. S, Sridhar. P. A Patient Satisfaction Survey in Public Hospitals. Journal of the Academy of Hospital Administration [2001-07 - 200112]; Vol. 13,No. 2

8. Kumar R, Srivastava J, Sharma L, Sodani P. Measuring patient satisfaction: A case study to improve quality of care at public health facilities. Indian $\mathbf{J}$ Community Med. 2010;35(1):52.

9. Abida Sultana, Rizwana Riaz, Sajid Hameed, Syed Arshad Sabir, Iffat Tehseen, Arshia Bilal and Maqsood Hayat. Patient satisfaction in emergency department of District Head Quarters Hospital, Rawalpindi. Rawal Medical Journal, 2010; Vol. 35, No. 1

10. Rahmqvist M. Patient satisfaction in relation to age, health status and other background factors: a model for comparisons of care units. International Journal for Quality in Health Care. 2001;13(5):385-390.

\section{How to cite this article?}

Bhoir L. N, Sarda A, Jhingan M. Evaluation of patient's satisfaction in the surgical units in a tertiary care public hospital. Int J Med Res Rev 2016;4 (6):1079-1085.doi: 10.17511/ijmrr.2016.i06.36. 